\title{
EL AGNOSTICISMO DE PROTÁGORAS
}

Angel J. Cappeletti

En Protágoras, como en otros sofistas, encontramos una filosofía de la religión. Y respecto a ella se han formulado no pocas apreciaciones erróneas o parciales. Los asertos de los Padres de la Iglesia, según los cuales Protágoras profesó el ateísmo y adquirió en su tiempo fama de "ateo", pueden considerarse frutos de una confusión conceptual y de una simplificación excesiva.

Epifanio afirma, por ejemplo, que nuestro sofista defendió la noexistencia de los dioses. ${ }^{1}$ Eusebio, el famoso historiador de la antigüedad eclesiástica, dice, en su Preparación evangélica, que Protágoras (a quien asocia, en este punto, con Demócrito) conquistó reputación de ateo. ${ }^{2}$

Pero no fueron sólo los escritores cristianos los que así interpretaron el pensamiento religioso de nuestro sofista. También en el mundo pagano, Diógenes de Enoanda afirma lo mismo que Epifanio y Eusebio, al escribir que Protágoras sostenía una tesis igual a la de Diágoras (el cual fue, sin duda, un ateo por todos conocido como tal), ${ }^{3}$ aunque no se atrevía a expresarla clara y abiertamente. ${ }^{4}$ Para Diógenes, lo mismo que para los mencionados Padres, el agnosticismo no pasa de ser una fórmula eufemística o vergonzante del ateísmo.

En cambio, Cicerón sabe distinguir con precisión entre Protágoras, que duda de la existencia de los dioses y la considera incognoscible, y los que, como Diágoras de Melos y Teodoro de Cirene, la niegan absolutamente. ${ }^{5}$

Con esta correcta apreciación parece concordar Filostrato. ${ }^{6}$ Pese a lo que diga Guthrie, ${ }^{7}$ el mismo Sexto Empírico no se siente muy seguro al identificar a Protágoras con los ateos, ya que escribe: "Con éstos (con

1 Epiph. Adv. Laer. III 2, 9.

2 Eus. Praep. ev. XIV 3, 7.

3 Cfr. Jacoby, Diagoras ó đ̌ $\theta \varepsilon o \zeta$ (Abh. Berl. 1959) pp. 3-8 (cit. por Guthrie).

4 Diog. Oenoand. Frg. 12, 2, 1.

5 Cic. De nat. deor. I 1, 2.

6 Philostr. Vit. soph. I 10, 2.

7 Guthrie, History of Greek Philosophy. Cambridge, III p. 234. 
Evemero, Diágoras, Pródico y Critias) convienen Teodoro el ateo y, según algunos, Protágoras." $8 \mathrm{El}$ ateísmo de nuestro sofista no representa, para él, sino la conjetura de ciertos autores, a la cual ni adhiere ni deja de adherir.

Sabemos por Cicerón que uno de los libros de Protágoras, ${ }^{9}$ titulado, según nos aclara Eusebio de Cesarea, ${ }^{10}$ Sobre los dioses ( $\pi \varepsilon \varrho \grave{~} \theta \varepsilon \tilde{\omega} v$ ), comenzaba precisamente con una proposición acerca de la incognoscibilidad de lo divino. Esta proposición, parafraseada por Filostrato, aparece también citada en Eusebio, en Hesiquio ${ }^{11}$ y en Sexto Empírico; ${ }^{12}$ pero, de un modo más completo, en Diógenes Laercio: "Acerca de los dioses no puedo saber ni si existen ni si no existen ni cuál es la forma esencial que tienen: muchas son, en efecto, las cosas que impiden el conocer esto, no solamente su propia oscuridad sino también el hecho de que la vida del hombre es breve." 13

La posición agnóstica de Protágoras queda, con estas ipsissima verba, bastante clara.

Sin embargo, no es suficiente distinguir a nuestro sofista de los ateos, como hemos hecho; es preciso diferenciarlo también de otro tipo de agnósticos que le precedieron. Estos fueron el predecesor y el sucesor de Parménides, es decir, Jenófanes y Meliso.

El segundo considera que no se puede decir nada acerca de los dioses, porque no es posible tener un conocimiento auténtico de los mismos. ${ }^{14}$ El primero, en uno de sus fragmentos, afirma que no hubo ni habrá nunca hombre alguno que posea un conocimiento cabal sobre los dioses. ${ }^{15}$

Este agnosticismo, derivado, por lo menos en Meliso, del carácter "opinativo" ( $\delta o ́ \xi \alpha)$ de "los dioses" (en plural), por oposición al carácter "verdadero" ( $\dot{\alpha} \lambda \eta \theta \hat{\eta})$ del conocimiento del Ser, tiene, sin duda, un sentido objetivo, y se expresa en proposiciones que pretenden, de por sí, una validez universal.

Pero se basa precisamente en el hecho de que, para Jenofanes y Meliso, los dioses necesariamente forman parte del mundo fenoménico, el cual no se puede captar con la razón.

El agnosticismo de Protágoras se funda, por el contrario, no en la afirmación de que sólo la razón puede conducir a la verdad sino, al con-

8 Sext. Adv. Math. IX 55.

9 Cic. De nat. deor. I 24, 63.

10 Eus. Praep. ev. XIV 3, 7.

11 Hesych. Onomat. in Schol. Plat. Resp. $600 \mathrm{c}$.

12 Sext. Adv. math. IX 56-57.

13 Diog. IX 51.

14 Diog. IX 24.

15 Sext. $A d v$. math. VII 49, 110; Plut. Aud poet. 2 p. 17 E, (21 B 34). 
trario, en la tesis de que no hay otra fuente del conocimiento más que la percepción sensorial.

Si se tiene en cuenta que la percepción sensorial nunca es errónea sino siempre verdadera para el sujeto que la experimenta, puede decirse que el agnosticismo tiene, pues, para él un sentido subjetivo (al revés del anterior). Quizá por eso la forma de la citada proposición inicial del tratado Sobre los dioses es, como advierte Guthrie, la de una opinión personal ("no puedo saber") y se contrapone así a la proposición agnóstica (o cuasi agnóstica) de Jenófanes. ${ }^{16}$

El agnosticismo de Protágoras debe ser entendido, ante todo, a la luz de su teoría del conocimiento.

Frente al flujo de fenómenos que constituye la realidad de la naturaleza, cada sujeto capta determinados momentos. Todo lo que capta existe y es verdadero para él. Protágoras afirma: Como yo no he percibido con mis sentidos a los dioses, no puedo decir que existen. Sin embargo, el flujo de la naturaleza es infinito y mi vida, demasiado breve, capta demasiado pocos fenómenos en ese flujo (tal vez los más evidentes y superficiales). Por eso, no me atrevo a afirmar tampoco que no existan. Mucho menos osaré decir algo acerca de su esencia o naturaleza.

En realidad, no deja de tener razón Jaeger, cuando hace notar que el pasaje que hemos citado "es una referencia a los dos principales problemas que habían ocupado a los filósofos presocráticos en lo que respecta a los dioses, los problemas de la existencia y de la forma de lo Divino". ${ }^{17}$

En efecto, la proposición citada se descompone en dos partes: en la primera, el autor expresa su opinión respecto a la no cognoscibilidad de lo divino; en la segunda, da las razones de esta opinión (las cuales, pese al alcance subjetivo que, como dijimos, tiene la afirmación, pueden ser utilizadas como fundamentos de una 'teoría agnóstica).

La primera parte se plantea, a su vez, como una oración principal ("no puedo saber"), que rige oraciones subordinadas, coordinadas disyuntivamente entre sí. Estas oraciones subordinadas, por su parte, constituyen dos unidades disyuntivas de primer grado ("ni si existen, ni si no existen" y "ni cuál es la forma esencial que tienen"). Dentro de la primera, como es fácil ver, hay todavía una disyunción de segundo grado ("ni si existen" y "ni si no existen").

Así, pues, en la primera parte (prótasis) la duda se plantea: 1) respecto a la existencia o no existencia de los dioses (adviértase que Protágoras no dice sólo no saber si éstos existen sino también no saber si no existen); 2) Respecto a su forma (i $\delta \delta \dot{\varepsilon} \alpha$ ), lo cual, como es evidente, por

${ }_{17}$ W. Jaeger, La teología de los primeros filósofos griegos, México, 1952, p. 189. 
el término empleado, alude a "aquello que hace que los dioses sean lo que son", esto es, a su esencia.

En realidad, en esta proposición con que iniciaba su obra Sobre los dioses, Protágoras no sólo hace referencia a "los dos principales problemas que habían preocupado a los filósofos presocráticos", en este terreno, sino, más todavía, a los dos principales problemas de toda la teología occidental, desde Anaximandro hasta Jaspers y desde Aristóteles hasta Whitehead, pasando por Anselmo de Canterbury, Tomás de Aquino, Descartes y Kant.

Un lector atento de los fragmentos protagóreos no puede dejar de preguntarse, sin embargo, si tiene en cuenta el contexto doxográfico, cuál sería el contenido de este tratado Sobre los dioses, cuando en su proposición inicial niega el autor la posibilidad de conocer nada sobre la existencia y la esencia de los mismos. ${ }^{18}$

No parece probable que la obra se ocupara, como sugiere Nestle, de refutar las pruebas corrientes entre el vulgo sobre la existencia de los dioses y su providencia.

Platón, por boca de Sócrates, le hace decir a Protágoras, en el Teeteto, que él ha prescindido totalmente, tanto en su enseñanza oral como en sus libros, de tratar cualquier problema concerniente a la existencia o no existencia de los dioses. ${ }^{19} \mathrm{Y}$ si el libro hubiera desarrollado la temática que Nestle supone, es claro que lo dicho por Platón sería falso. Si se tiene en cuenta que en el mito del Protágoras, nuestro sofista, quien, sin duda, valora positivamente el vónos y la cultura en general, considera el culto de los dioses como rasgo específico de la especie humana y como inmediata consecuencia de sus primeros progresos técnicos (que en el mito son un privilegio divino), parace lógico suponer que la obra está dedicada a mostrar las variedades de la religiosidad griega y bárbara $y$, sobre todo, el papel que en las diversas sociedades ha desempeñado la religión.

El Sobre los dioses tendría así un carácter histórico-sociológico. Supondría, en primer lugar, un estudio comparado de las mitologías y los cultos, en cuya elaboración Protágoras pudo haber utilizado obras de historiadores anteriores a él, como Herodoto y Hecateo, y también investigaciones, y experiencias personales, como las que tal vez tuvo en su niñez, al entrar en contacto con los "magos" persas.

Pero supondría, además, la tesis de la necesidad de la religión como parte de la cultura y como elemento mediante el cual el vónos asegura la vida del hombre en la Sociedad y el Estado. "Esta manera de abordar la cuestión tuvo que ser también extremadamente simpática a las

18 Cfr. Guthrie, op. cit., III pp. 234-235.

19 Plat. Theaet. $162 \mathrm{D}$. 
tendencias de aquellos tiempos; pues a pesar de toda la crítica racionalista y toda la incertidumbre corriente, habia un sentimiento creciente de que la religión era indispensable, y la opinión pública se estaba volviendo sensible como nunca antes a los reales y los presuntos ataques contra los dioses del Estado", dice Jaeger. ${ }^{20} \mathrm{Y}$ añade: "Pero este conservadurismo tuvo que venir enteramente del lado de la moral y de la política práctica."

Algo semejante habia de suceder siglos más tarde con Saint-Simon y su "Nuevo cristianismo", con Augusto Comte y su "Religión de la humanidad". A pesar de la demoledora crítica de la Enciclopedia, en la Europa de la primera mitad del siglo xIX no sólo la nobleza sino también la ascendente burguesía sentía la necesidad de afirmar el valor de la religión en la Sociedad.

De ahí surgieron, por un lado, las "apologías" de creyentes, como De Bonald y Lammenais; por otro, las "apologías" de agnósticos, como Saint-Simon y Comte.

Un texto de las Bacantes de Eurípides, que Nestle considera como una alusión polémica contra el agnosticismo de Protágoras, ${ }^{21}$ parecería más bien resumir la posición de éste frente a la religión y frente a la crítica filosófica radical:

Cadmo: No desprecio a los dioses, pues mortal he nacido.

Tiresias: No tejamos sofismas en torno a las deidades. Las patrias tradiciones, tan viejas como el tiempo, no podría destruirlas ningún razonamiento, aun cuando un gran sabio encontrara una prueba. ${ }^{22}$

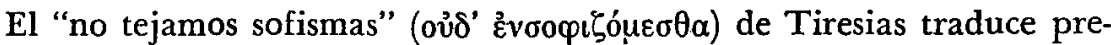

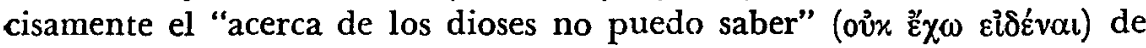

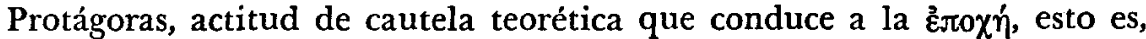
al agnosticismo. Toda teología y todo ateísmo, en efecto, suponen "un tejer sofismas", en el sentido de "sutilizar" y "dogmatizar". ${ }^{23}$

20 W. Jaeger, op. cit., p. 189.

21 Cfr. Nestle, Euripides der Dichter der griechischen Aufklärung. Stuttgart, 1901, p. 84 .

22 Eurip. Bacch. 199-203.

23 Cfr. W. Jaeger, Humanism and Theology. Conf. Aquin., 1943. 